\title{
A Study on the Case and Performance Analysis of the College of Physical Education of ${ }^{『}$ Team Team Class』
}

\section{창의융복합 교육모델인『팀팀Class』의 체육대학 운영사례와 성과분석 연구}

Young Hee $\mathrm{Cho}^{1}$

조영희 1

${ }^{1}$ Professor, Department of Sport Educaiton, Kookmin University, Korea, choyh@kookmin.ac.kr

\begin{abstract}
The purpose of this study was to introduce community-linked classes of Physical Education(PE) students who participated in "Team Team Class", a creative convergence education model of K University, and to provide basic data of the university convergence education model through performance analysis. The research contents are as follows. First, an introduction to K University's convergence education "Team Team Class", and examples of classes in which actual Physical Education(PE) students connected with the local community are introduced. Second, "Team Team Class" by PE students, elderys of the local community, and participating professor was analyzed. The subjects of the study were 15 students from the PE college, 11 elderys from the welfare center, and 1 professor, focusing on the class case of "Team Team Class". The results of this study are as follows; First, PE students improved their ability to develop, plan, teach, and operate health programs for the elderly. Through teacher's experience, understanding of the elderly, and exercise, as well as nutritional approaches, it provided an opportunity to expand the study and introduce and apply it to the major field. Second, it was an opportunity for the elderly to participate in the health care (exercise-nutrition) program that students directly visit and to feel physical, social, and psychological satisfaction with exercise and nutritional education. Lastly, by finding commonalities between the two majors together, the professor as well as students recognize the need for connection between the field and the major, connect with the local community, analyze from various perspectives, and create a convergence education system. It was also an opportunity for research, and provided an opportunity to consider the direction of leading the era of convergence through expansion of major.
\end{abstract}

Keywords: University Convergence Education Model, Team Team Class, Health Program, College of Physical Education Students

요약 : 4차 혁명 시대와 함께 교육의 현장에서도 창의융합 인재 양성이 필요로 하며 대학교육 의 현장 역시 새로운 교육시스템이 시도되고 있다. 본 연구의 목적은 $\mathrm{K}$ 대학교 창의 융복합 교 육모델인 『팀팀Class』에 참여한 체육대학 학생들의 지역사회 연계 수업을 소개하고, 성과분 석을 통해 대학 융복합 교육모델의 기초자료를 제공하는 데 있다. 연구내용은 다음과 같다. 첫 째, K대학교 융복합 교육『팀팀Class』소개 및 실제 체육대학 학생들이 지역사회와 연계한 수

Received: September 5, 2021; $1^{\text {st }}$ Review Result: October 21, 2021; $2^{\text {nd }}$ Review Result: December 7, 2021 Accepted: January 29, 2022 
업 적용사례 소개, 둘째, 체육대학 학생, 지역사회 어르신, 참여교수에 의한 『팀팀Class』의 성과 파악이다. 연구대상은 코로나19로 인해 2020년-2021년은 가장 취약계인 노인분들의 안전 을 위해 복지관 출입의 제한으로 2018년, 2019년에 진행된 지역사회복지관과 함께했던 K대학 교 창의융복합 교육시스템인 『팀팀Class』 수업사례를 중심으로 분석하였다. 본 연구의 결과 는 다음과 같다. 첫째, 체육대학 학생들은 실제 어르신들에게 건강프로그램 개발, 계획, 티칭, 운영하는 능력을 향상시키고, 현장의 노인체육 지도자 역할체험, 지도 대상(노인) 파악, 운동뿐 아니라 영양학적인 접근을 통해 학문의 확장과 전공영역에 도입 및 적용할 수 있는 기회를 제 공하였다. 둘째, 지역사회 연계프로그램으로 어르신들은 학생들이 직접 찾아가는 건강관리(운 동-영양)프로그램에 참여하시고 신체적, 사회적, 심리적인 만족감을 느낄 수 있는 기회가 되었 다. 마지막으로 담당 교수는 두 전공의 교수가 함께 두 전공간의 교집합을 찾아냄으로써, 현장 과 전공연계성의 필요성 인식, 지역사회와의 연계 및 다양한 관점에서 분석하고 융복합 교육 시스템을 만들어가야 한다는 점에서 학생들 뿐만 아니라 교수입장에서도 연구의 기회이며, 전 공확장을 통해 융합의 시대를 이끌고 나가는 방향을 고민하는 계기를 마련할 수 기회를 제공 하였다. 창의융복합 교육모델인 $\mathrm{K}$ 대학교『팀팀Class』는 현장중심의 융복합 학문의 접근으로 체육대학 학생들이 현장에서 영양학적으로 접근할 수 있는 새로운 전공의 영역확장의 기회였 으며 앞으로도 또 다른 전공 영역과의 융복합 교과과정 연계를 통해 학생의 취업, 창업 및 교 수역량 확대, 지역사회의 발전까지도 가져올 수 있도록 지향할 필요가 있는 교육시스템이라 사료된다.

핵심어: 융복합교육모델, 팀팀Class, 체육대학학생, 건강관리프로그램

\section{1. 서론}

교육부[1]는 4차 산업혁명 시대를 이끌어나갈 수 있는 창의융합인재 양성을 위한 교육과정 개편, 교육 및 연구 혁신을 통해 대학의 지식, 기술을 활용한 가치 창출 및 대학 역량을 강화하고자 하였다. 대학생들의 전공 분야의 지식과 다양한 분야와의 창의적인 협업과 소통은 융합적인 지식 창출과 현장적용 등의 새로운 융합분야의 창의융합인재를 양성할 수 있는 교육이 될 수 있다. 대학은 전공과 타전공과의 관계성을 학습하고, 융합하여 전략적인 수업과 프로그램 등의 교육이 필요하다[2].

대학생들은 제한된 전공지식에만 집중하지 않고 다양한 지식과 정보를 학습하면서 자연스럽게 융합을 시도하여 새로운 융합적 가치를 창출할 수 있는 창의융합역량을 지닌 인재로 육성되어야 한다[3]. 또한 대학은 지식기반사회를 이끌어갈 창의융합적인 인재를 원하고 있으며, 체험교육을 실시함으로 교육의 전환을 이루어야 한다[4].

융합교육, 융복합 교육이라는 것은 서로 다른 교과 간에 관련되는 요소를 새로운 교과로 조직하여 융합시킴으로써 성립하는 교육이다[5]. 미국에서도 4차 산업혁명 시대를 맞이하여 창의융합 인재양성의 중요성을 강조하고 있으며, 노스캐롤라이나 주립대학교는 그래픽, 수학, 기술, 공학, 과학, 설계 등의 융합 교육과정을 운영하고 있다[6]. 4차 산업혁명 시대에 IoT(사물인터넷), 인공지능, 웨어러블, 빅데이터 등의 핵심 요소들을 적극 활용할 것을 기대했으며, 새로운 플랫폼(VR, $\mathrm{AR}$ 등)의 확산과 함께 교육의 현장에도 새로운 교육모델(MOOC, 플립러닝, Zoom 수업 등)이 계획, 진행되고 있다[7]. 또한 현재는 코로나 19와 함께 비대면 활동이 진행되면서 대학 융복합교육 콘텐츠들의 개발 및 
연수가 필요한 시점이다.

이러한 시대적 흐름 속에서 우리나라도 새로운 대학 교육의 패러다임을 위해 산학협력의 중요성을 강조하고 있으며, 창의융합 인재양성을 위해 창의융복합 교육모델인 $\mathrm{K}$ 대학교 『팀팀Class』는 두 개의 학과의 수업을 동시에 수강하면서 융복합적인 교육을 받는 혁신적인 교육방식으로 지역사회와의 연계 활동을 통해 실용적인 융합 교육을 경험할 수 있는 교육이라 할 수 있다.

따라서 본 연구는 K대학교가 2017학년도부터 국내 대학 최초로 설계한 융합 교육 프로그램이자, 가장 특화되어 있는 학습 커리큘럼인『팀팀Class』를 소개하고, 체육대학 학생들의 식품영양 학생들과의 수업참여 사례 소개를 통해 체육대학 학생들의 입장에서『팀팀Class』의 성과를 분석하고 효과를 파악하며, 체육대학 학생들을 위한 융복합 교육과정과 나아가 대학의 교육모델의 기초자료를 제공하고자 한다.

\section{2. 창의융복합 교육모델 『팀팀Class』}

\section{1 『팀팀Class』 융복합 교육}

『팀팀Class』는 K대학교에서 2017학년도부터 시작한 융합 교육으로 실용주의와 공동체 정신을 실현하는 창의융복합 교육모델로서, 기존의 학문영역, 교과, 비교과의 고정관념을 탈피하여 서로 다른 학과의 학생들이 이질적인 두 과목을 동시에 수강하게 하는 국내 최초의 혁신적인 창의융복합 교육모델이다. 학생들은 2 개의 교과목을 동시에 수강하게 되고 서로 다른 두 분야를 유기적으로 융합하여 전 공간 경계를 넘는 하나의 교과목이 생성되어, 그 수업 내에서 Tutorial Class(2명의 교원이 동시에 수업에 참여하여 다양한 관점에서 특정 주제에 대해 분석, 토론하는 수업), 사회연계 활동을 통해 실용적 융합교육을 경험할 수 있게 하는 시스템이다[8]. 이처럼 전혀 다른 분야의 학문 간의 융합을 통해 나의 전공에서 생각해내지 못했던 분야까지 새롭게 발견해 내는 혁신적인 아이디어 발상의 장이 될 수 있다. 공통의 과제를 해결하기 위해 다른 전공 공부를 함께하면서 자연스럽게 융합적 사고를 끌어낼 수 있으며, 전공을 좀 더 깊이 있게 확장시킬 수 있다. 이론적인 전공의 융합만이 아닌 지역사회와의 연계 활동을 통해 자신이 속한 공동체, 지역사회의 문제를 해결할 수 있는 인재양성, 사회와 국가와 함께 함께 협업하여 해결책을 제시하여 변화를 만들어내는 제반 활동이라 볼 수 있다[8]. 학생들이 수강신청 시 『팀팀Class』수업으로 묶인 두 교과과정을 동시에 수강해야 하여 타전공의 수업을 함께 수강해야 하는 부담이 있으나, 수강인원의 최대 $40 \%$ 까지 A학점을 받을 수 있고, 전체 $\mathrm{B}$ 학점 이상을 받을 수 있다는 장점이 있어 학생들이 수업에 집중 할 수 있게 한다는 장점이 있다.

\section{3. 연구방법}

\section{1. 연구대상}

본 연구는 『팀팀Class』교육모델을 소개하고, 수업에 참여한 체육대학 학생, 어르신, 교수를 대상으로 성과를 분석하였다. 이를 위해 2018-2019년에 이 수업에 참여한 체육 대학 학생 15 명, 식품영양학과 13 명, 바이오발효융합학과 11 명, 65 세 이상 지역사회 어르신 11 명, 교수 3 명 중 본 연구의 사례소개와 체육대학 학생들이 참여한 팀팀Class에 
대한 성과분석 및 체육교과 융복합 교육모델을 위해 본 연구분석에 활용한 연구대상은 체육대학 학생 15명, 어르신 11명, 체육대학 교수 1명으로 진행하였다[표 1].

[표 1] 연구 대상

[Table 1] Research Object

\begin{tabular}{|c|c|c|c|c|c|}
\hline \multirow[t]{2}{*}{ 대상 } & \multicolumn{2}{|c|}{$\begin{array}{c}\text { 대학생 } \\
\text { (체육대학 스포츠교육학과) }\end{array}$} & \multirow{2}{*}{\multicolumn{2}{|c|}{$\begin{array}{c}\text { 어르신 } \\
\text { (J복지관- 엑티브 시니어 } \\
\text { 건강관리프로그램 참여자) }\end{array}$}} & \multirow{2}{*}{$\begin{array}{c}\text { 교수 } \\
\text { (체육대학 스포츠교육학과) }\end{array}$} \\
\hline & 2018년 & 2019년 & & & \\
\hline \multirow{3}{*}{$\begin{array}{c}\text { 매 } \\
\text { 2학기 }\end{array}$} & \multirow{3}{*}{$\begin{array}{l}9 \text { 명 } \\
\text { (남9) }\end{array}$} & \multirow{3}{*}{$\begin{array}{c}\text { 6명 } \\
\text { (여1, 남5) }\end{array}$} & 90세이상 & 2명(여) & \multirow{3}{*}{ 1명(여) } \\
\hline & & & 80-89세 & 6명(여5,남1) & \\
\hline & & & 70-79세 & 3명(여) & \\
\hline 합계 & \multicolumn{2}{|c|}{ 15명 } & \multicolumn{2}{|c|}{ 11명 } & 1명 \\
\hline
\end{tabular}

\section{2 연구절차}

체육대학 학생들이 참여한 『팀팀Class』운영사례를 소개하고 성과분석을 위한 연구절차는 [그림 1]과 같다. 코로나19로 인해 2020년-2021년은 가장 취약계인 노인분들의 안전을 위해 복지관 출입의 제한되어 본 연구는 2018-2019년 2년에 걸쳐 이루어진 “엑티브 시니어 건강관리프로그램 개발”이라는『팀팀Class』의 운영사례를 통해 융복합 교과과정의 소개와 성과를 분석하였다.

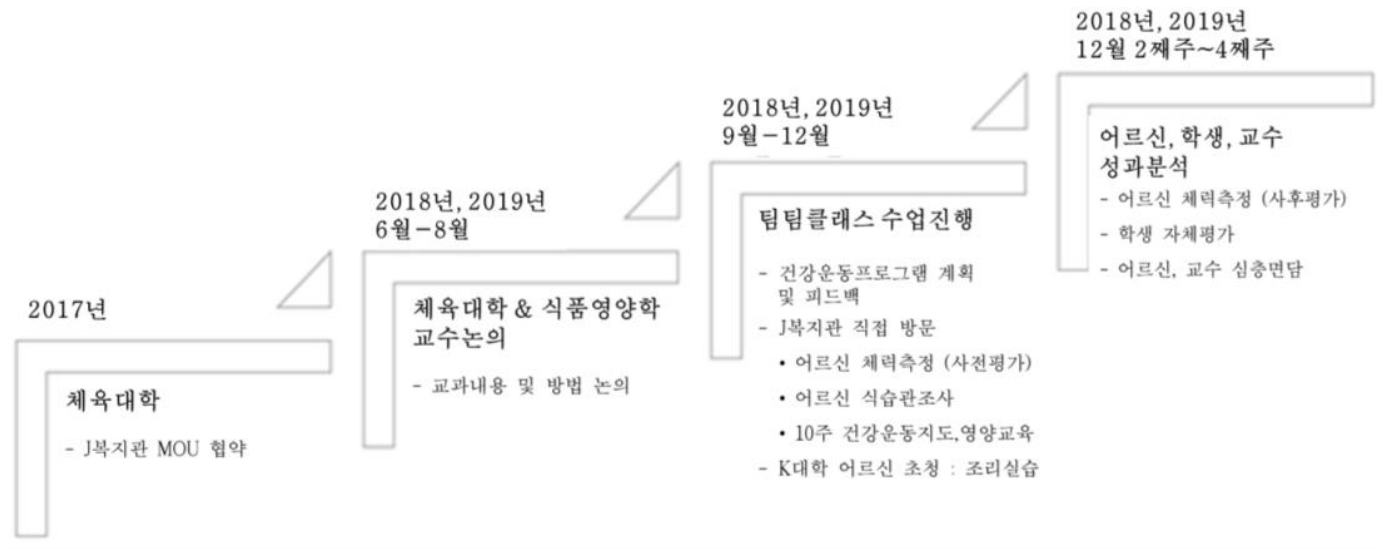

\section{[그림 1]『팀팀Class』운영 절차}

[Fig. 1] Procedure of ${ }^{『}$ Team Team Class』

\section{3 연구도구 및 자료분석}

체육대학 학생들이 참여한 『팀팀Class』운영사례 소개를 위해 $\mathrm{K}$ 대학교 홈페이지[8] 및 팀팀클래스에 관련된 선행연구[9][10]을 기반으로 하여 체육대학 학생들이 실제 참여한

『팀팀Class』의 실제 사례를 소개하였다.

체육대학 학생들이 참여한 『팀팀Class』성과분석을 위해 학생들의 자체평가 내용은 10 주간의 실제 건강관리 프로그램에 대한 평가 내용으로 프로그램 기획, 운영하는데 필요한 문항으로 진행, 역할분담, 프로그램의 적절성, 어르신의 호응도의 5 문항을 5 점 
척도로 자체 제작하여 기술통계를 통해 평균 점수를 기재하였다.

어르신들의 성과분석을 위해 국민체력 100 체력인증센터[11]와 Senior Fitness Test[12]의 체력 측정 요인인 하체 근력(의자에 앉았다 일어서기, 회 $/ 30$ 초), 상체 근력( $2.5 \mathrm{~kg}$ 덤벨 들어올리기, 회/30초), 유산소(2분 제자리 걷기, 회/2분), 유연성(앉아서 윗몸 앞으로 굽이기, $\mathrm{cm}$ ), 평형성(의자에 앉아 $3 \mathrm{~m}$ 표적 돌아오기, 초)의 사전사후 측정하고 $\mathrm{t}$-test를 통해 사전, 사후 향상도를 비교하였다.

어르신과 교수의 성과분석 조사를 위해 심층 면담을 진행하였다. 어르신과의 심층 면담은 질문지 없이 연구자와 연구참여자가 대화 형태로 면담하는 비구조화된 면담을 진행하였고, 교수자와의 심층 면담은 미리 만들어진 질문지를 사용하여 반구조화된 면담으로 진행되었다. 어르신들은 사후 체력 측정시 $1: 1$ 로 직접 면담으로 진행되었으며, 교수자와 어르신 간에는 2016년도부터 체육대학 수업 연계를 통해 Rapport 형성이 되어 있는 상태이므로 $\mathrm{J}$ 복지관에서 편안한 분위기에서 진행되었다. 교수자는 인터뷰 기사[13]를 참고하고, $1: 1$ 직접 면담으로 진행되었다.

\section{4 체육대학 학생들이 참여한『팀팀Class』사례소개}

체육대학 스포츠교육학과의 시니어 스포츠 프로그램 개발과 과학기술대학 식품영양 학과의 실버헬스케어라는 수업의 만남을 통해 “엑티브 시니어 건강관리프로그램 개발”이라는 새로운 교과목의 탄생으로 지역사회 복지관과의 연계를 맺어 어르신을 위한 체육학적 접근과 영양학적인 접근을 동시에 학습하였다. 본 연구를 위해 2018-2019년에 실시된 수업사례를 소개하고자 한다[표 2].

[표 2]『팀팀Class』의 수업 내용

[Table 2] Contents of ${ }^{『}$ Team Team Class』

\begin{tabular}{|c|c|}
\hline 수업명 & $\begin{array}{c}\text { 팀팀Class : 엑티브 시니어 건강관리프로그램 개발 } \\
\text { (지역사회기관 연계 프로그램 계획) }\end{array}$ \\
\hline 학과 & 과학기술대학 \\
\hline 수업시간 & 2학점 (3시간) \\
\hline 수업개요 & $\begin{array}{l}\text {-“시니어스포츠프로그램개발’수업을 통하여 노인의 신체적 특징에 따른 적합한 운동방법을 학 } \\
\text { 습 } \\
\text {-실버헬스케어’수업을 통하여 노화, 만성질병, 노년기 식생활 특징을 파악하고 식생활개선프 } \\
\text { 로그램 개발 및 학습 } \\
\text { - 두 과목을 통하여 노인 영양 및 운동관리 프로그램 개발, 종합적 노년기 건강관리 프로그램 } \\
\text { 개발방법을 학습시키고자 함. }\end{array}$ \\
\hline 수업목표 & $\begin{array}{l}\text { - 고령화 사회의 시니어의 건강유지와 증진을 위한 지속적인 스포츠활동을 조사하고 운동프로 } \\
\text { 그램 개발 및 실제 티칭법 배움. } \\
\text { - 노인 질환을 예방.치료할 수 있는 영양학적 지식과 기술을 습득하고 이를 바탕으로 식생활 } \\
\text { 개선프로그램을 개발할 수 있도록 함. }\end{array}$ \\
\hline 기대효과 & $\begin{array}{l}\text { - 융합적 사고와 분석 능력 향상 (노인대상의 이해 및 건강관리 지도를 위한 역할체험과 진로 } \\
\text { 파악, 영양 및 운동학적 관점 동시 적용 및 해결) } \\
\text { - 협동학습능력 향상 (팀별 프로젝트 수행) }\end{array}$ \\
\hline
\end{tabular}

노인 운동 관리 및 영양 프로그램 개발 교육을 통합하여 종합적 노년기 건강관리 프로그램을 개발하고 학습하는데 목표를 두고 매 2 학기에 엑티브 시니어 건강관리 
프로그램 개발 수업은 $\mathrm{J}$ 사회복지관에서 이루어졌으며, 영양과 운동학적 관점을 동시에 적용하여 융합적 사고와 분석 능력을 도모하였다. 또한 지역사회와 학교를 연계시켜 학생들은 노인스포츠 지도 및 영양사 역할을 체험함으로써, 지도대상인 어르신에게 영양적인 식단과 운동의 방향을 제공할 수 있었다.

“엑티브 시니어 건강관리프로그램 개발” 수업시간, 개요, 목표 및 기대효과는 [표 2]와 같다. 본 연구의 활동인 『팀팀Class』는 사전측정을 통해 두 학과의 특징에 따라 체력 측정과 식습관 조사를 실시하였다. 이에 운동학적인 측면과 영양학적인 측면에서 부족한 부분을 파악하고, 실제 어르신들에게 필요한 건강관리프로그램을 적용하기 위해 4주간의 운동프로그램 이론 및 실습, 토의 및 논의가 진행되었고, 식생활 개선 프로그램 및 조리 메뉴를 선정하였다. 이후 실제 운동프로그램 적용(10주 동안 주 1 회 및 5 회의 홈트레이닝 과제) 및 영양 교육, 조리 실습을 통해 어르신들의 건강관리를 위한 프로그램을 개발하였다. 건강관리 프로그램의 내용은 사전측정을 통해 체력은 평형성과 유연성 향상을 위한 프로그램으로, 식품영양은 식습관 조사 결과, 노인의 권장 섭취량인 $1,600 \mathrm{kcal}$ 에 비해 실제 섭취량이 $1,037 \mathrm{kcal}$ 로 파악되어 $200-400 \mathrm{kcal}$ 의 간식을 개발하게 되었으며, 운동과 식품 모두 대상자의 질병(고혈압, 당뇨)을 고려하여 나트륨을 줄일 수 있는 칼슘 성분과 비타민 성분의 간식을 개발하고 운동의 접근 역시 질병에 유의해야 할 점을 고려하여 지도하였다. 매주 자체평가를 통해 부족한 부분, 잘한 부분들을 서로 논의하고 채워가며 실제 건강관리프로그램 개발에 도움을 줄 수 있었다. 마지막으로 체력 사후측정을 통해 실제 체력변화에 대한 피드백과 현재 식습관 분석을 통해 올바른 식습관에 대한 피드백까지 제공하였다[그림 2].

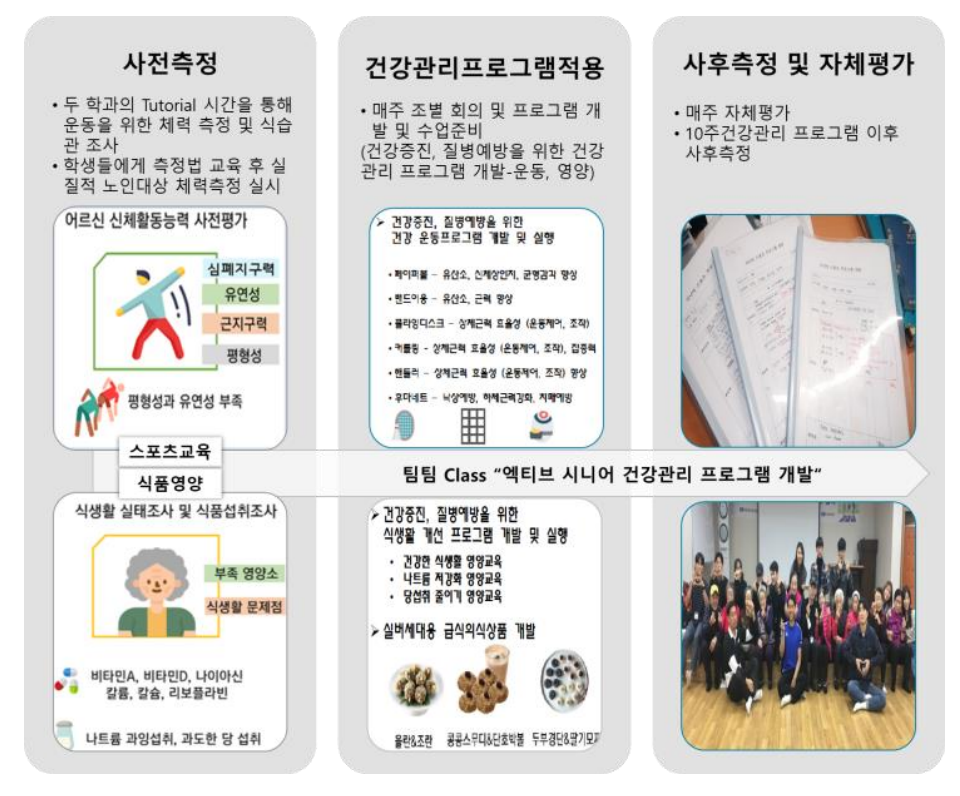

[그림 2] 체육대학 학생들이 참여한 『팀팀Class』 내용

[Fig. 2] Contents of ${ }^{『}$ Team Team Class』

\section{4. 연구결과 및 논의}

\section{1 체육대학 학생들이 참여한『팀팀Class』성과 분석}

본 연구는 체육대학 학생들이 참여한 『팀팀Class』의 성과를 분석하기 위해 연구대상 
중 체육대학 학생 15 명의 자체평가내용 분석과 어르신 11 명 건강관리 분석 및 의견, 체육대학의 운영사례 및 성과분석을 위해 체육대학 교수 1 명의 의견을 토대로 성과분석을 실시하였다.

\subsection{1 체육대학 학생들의 성과 분석}

자체평가 내용은 10 주간의 실제 건강관리 프로그램에 대한 자체평가 내용으로 진행, 역할분담, 프로그램의 적절성, 어르신의 호응도를 5 점 척도로 자체제작하여 진행하였다.

결과는 다음과 같다. 체육대학 학생들이 평가하는 자신들의 진행도는 4점으로 잘한다고 평가하였다. 실제 어르신을 대상으로 지도해 본 경험이 없는 학생들이 수업 전 모의수업을 통해 연습과 피드백으로 실제 지역사회 어르신 운동을 지도하는 지도자의 역할을 충실히 했다는 결과이다. 또한 학생들과 교수 피드백을 통한 프로그램의 적절성과 어르신들의 호응도는 4.5점으로 매우 만족함에 가까운 결과를 나타냈다. 마지막으로 『팀팀Class』를 통해 조원 역할 분담을 통해 소통 및 토의, 실제 진행까지 4.2점으로 잘했다는 자체평가를 나타냈다. 즉, 이러한 『팀팀Class』의 창의 융복합 교육시스템을 통해 전반적으로 높은 자체평가 결과를 가지고 옴으로써 체육대학 학생들은 실제 어르신들에게 건강관리프로그램 개발, 계획, 티칭, 운영하는 능력을 향상시키고, 현장을 직접 체험함으로 체육지도자 역할체험, 전공에 대한 적성 파악, 지도 대상 파악, 운동뿐 아니라 영양학적인 접근을 통해 학문의 확장과 전공영역에 도입능력을 학습할 수 있는 경험이 될 수 있었다[그림 3]. 그 외 기타 주관적 의견으로는 어르신에 대한 이해, 친밀감 형성의 중요성, 운동 계획, 운영 방법, 지도 경험, 노인스포츠 지도자 역할 경험의 소중함을 느낄 수 있었다는 학생들이 많았다.

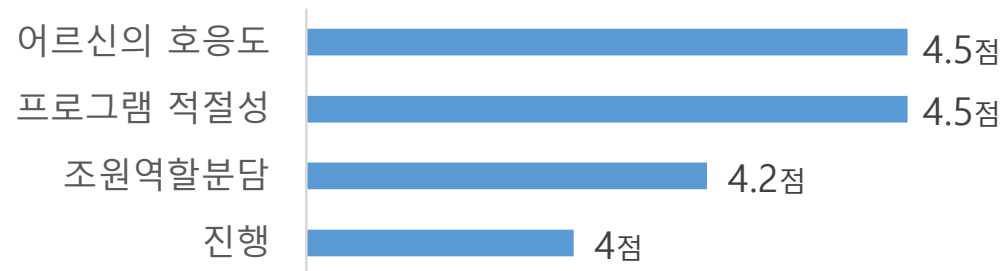

[그림 3] 체육대학 학생들이 참여한 『팀팀Class』자체평가 내용

[Fig. 3] Self-evaluation of ${ }^{『}$ Team Team Class』

\subsection{2 체육대학 학생들과 함께 『팀팀Class』에 참여하신 어르신들의 성과분석}

지역사회 연계프로그램으로 11 명의 65 세 이상의 어르신이 계신 $\mathrm{J}$ 복지관을 학생들이 직접 찾아가는 건강관리 운동 교실에 참여하심으로 첫째, 체력 향상을 확인할 수 있었다[그림 4].

기본적인 근력과 심폐 지구력 향상과 함께 사전측정 시 부족한 체력 확인 및 프로그램 방향에 대한 피드백(유연성과 평형성에 대한 프로그램계획 필요)을 통해 프로그램을 구성하였고, 사후 측정 시 모든 영역에서 사전 측정보다 향상된 측정값을 나타낸 것을 확인 할 수 있었다. 특히, 상체 근력 $(\mathrm{p}<.001)$ 과 유연성 $(\mathrm{p}<.05)$ 은 통계적으로 유의하게 향상된 결과를 나타냈다. 


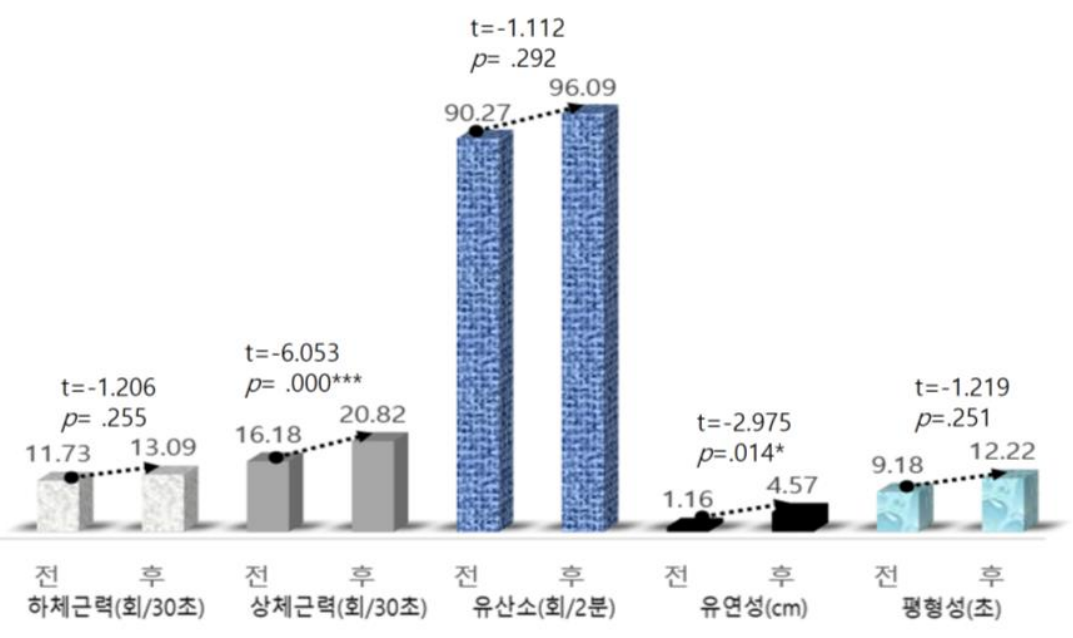

[그림 4]『팀팀Class』참여하신 어르신들의 체력향상도

[Fig. 4] Physical Fitness of the Elderly who Participated in ${ }^{『}$ Team Team Class』

또한 $1: 1$ 심층 면담을 통해 어르신들의 신체적 향상도 뿐만 아니라 사회적, 정서적 만족감의 향상도를 확인할 수 있었다. 심층 면담 결과 사회적, 정서적 만족감 향상에 대한 면담내용을 발췌하면 [표 3]과 같다.

[표 3]『팀팀Class』참여하신 어르신들의 면담내용

[Table 3] Interview Contents of the Elderly who Participated in ${ }^{『}$ Team Team Class $\Perp$

\begin{tabular}{l} 
어르신들의 면담내용 \\
\hline 병원을 가야하는데 오늘 운동이랑 겹쳐서 병원도 안가고 왔어. 오늘 못보면 학생들도 못보고 선생님 \\
도 못보니까 병원도 안가고 왔어. \\
\hline 10 번만 온다했나요? 더 오면 안되나? 작년에도 10 번 보고 1년을 기다렸는데, (울먹이시면서) 보고싶 \\
어서 어쩌지. 선생님이라도 방학때 오면 안되나? \\
우리처럼 안되는 사람 가르치느라 수고가 많아요. 잘 못해서 답답할텐데 애씁니다. \\
우리 교수님과 학생선생님들 밥도 안먹고 왔을 것 같은데 우리 노인네들 가르치려고 밥은 먹고 다 \\
녀요? (간식 쥐어주시며) 이거라도 가져가서 먹으면서 하면 내 맘이 편할 것 같아 \\
내가 늙었어도 할 수 있어. 너무 재밌고, 나도 잘하는 거 보여주고 싶고, 내가 저 양반 보다 더 잘 \\
할 수 있지. 너무 즐겁네 \\
복지관에 밥먹으려고 왔는데, 요즘에는 운동하는 날 기다려져서 오늘같이 운동하는 날은 밥 먹을때 \\
부터 선생님이랑 학생들 오는 시간을 많이 기다리고 있어요. 너무 즐겁고, 또 와요. 더 많이 오면 \\
좋겠네.
\end{tabular}

창의융복합 교육모델 『팀팀Class』를 통해 지역사회 어르신들이 학교의 학생들과 함께 프로그램을 참여하면서 병원도 가지 않고 오실 정도로 심리적으로 즐겁고, 함께 만남에 대한 기대감, 계속 만남을 유지하면서 수업을 하고자 하는 기다림 등에서 정서적, 사회적 만족감을 확인할 수 있었다. 또한 수업에 대한 즐거움을 나타내시는 어르신들을 보며 정서적으로나 사회적으로 외롭고 우울하신 어르신들에게 큰 만족감을 느끼게 한 수업이라 할 수 있다. 이는 선행연구[14][15] 등에서 신체활동, 운동을 통해 정서적 만족감에 긍정적인 영향을 준 연구들을 뒷받침하는 결과이며, 어르신들이 신체활동 및 운동을 통해 신체적, 정신적, 사회적 건강 유지뿐만 아니라 생활 만족에도 긍정적인 
영향을 미친다는 선행연구[16]처럼 본 연구의 면담 내용을 통해 운동의 기간, 운동 참여 정도요인 등의 변인만이 아닌 학생들과 함께 할 수 있는 기회만으로도 정서적 행복감과 만족감, 사회성을 느끼는 결과를 볼 때, 학교-지역사회와 연계된 『팀팀Class』교육모델 적용은 지역사회 어르신들의 신체적 향상 뿐 아니라 사회적, 정서적 행복감을 가져다준 의미 있는 결과이며 나아가 생활 만족과 긍정적인 연계를 가져다줄 수 있는 활동이라 사료된다.

\subsection{3 체육대학 학생들이 참여한 『팀팀Class』에 대한 교수의 성과분석}

구조화된 질문지를 통해 첫째, 『팀팀Class』가 가져다준 교수자로서의 장점은 두 전공의 교수가 함께 두 전공 간의 교집합을 찾아내야 하고, 현장과 연계성의 필요성에 대한 인식도 해야 하며, 2 명의 교원이 동시에 수업에 참여하여 다양한 관점에서 특정 주제에 대해 분석과 토론을 해야 하는 Tutorial class를 제공해야 하는 융복합 교육 시스템을 만들어가야 하는 점에서 학생들뿐만 아니라 교수 입장에서도 새롭게 공부할 수 있는 시간이며, 전공을 확장하여 융합의 시대를 이끌고 나가는 교육의 방향을 고민하는 계기를 마련할 수 있는 기회라 했다. 앞으로 코로나 시대에 체육대학 학생들이 또 다른 콘텐츠를 통해 융복합시대에 자신의 전공을 다른 분야와의 융합할 수 있는 전공 확장은 중요한 부분이므로 교수자의 연구 및 개발은 중요할 것으로 보여진다.

둘째, 『팀팀Class』에 참여한 교수자로써의 기대효과는 창의융복합 교육모델인 K대학교 『팀팀Class』를 기반으로 하여 전공 확장된 융복합 학문의 접근은 체육대학 학생, 교수, 지도대상자들, 나아가 지역사회의 발전까지도 가져올 수 있을 것으로 기대한다. 또한 이러한 융복합 교육과정의 적용은 대학교육에서의 적용과 전공영역에 기초한 통합적 영역확장을 통해 창의적인 문제해결 능력을 갖추는 인재를 양성할 수 있는 기회가 될 것[9]으로 판단되고, 각 전공의 교수 및 대학이 함께 해야 할 과제이다. 이는 뉴 노멀(New Normal) 시대 새로운 각 전공이 영역에서 융합 교육의 새로운 방향 설정에 도움이 될 수 있을 것[10]으로 사료된다.

\section{5. 결론 및 제언}

4차 혁명 시대, 코로나 시대인 현시대에는 융복합의 교육체계가 필요한 시점이다. 창의 융복합 교육모델인 $\mathrm{K}$ 대학의 『팀팀Class』는 전공의 심화 과정이 될 수 있는 융복합 학문이며, 학생, 지역사회, 교수가 연합하여 새로운 지역사회의 문제를 해결할 수 있는 인재양성, 사회와 국가와 함께 협업하여 해결책을 제시하여 변화를 만들어내는 제반 활동이다[8]. 본 연구를 통해 체육대학 학생들이 참여한 『팀팀Class』의 성과분석은 다음과 같다.

첫째, 창의융복합 교육모델인 『팀팀Class』는 체육대학 학생들에게 실제 현장 지도자 역할 체험의 기회, 지도 대상(노인) 파악, 운동뿐 아니라 영양학적인 접근을 통해 학문의 확장과 전공영역에 도입 및 적용할 기회를 제공하였다.

둘째, 창의융복합 교육모델인 『팀팀Class』는 지역사회 연계프로그램으로 어르신들에게 학생들이 직접 찾아가는 건강관리(운동-영양)프로그램에 참여하심으로 질병 맞춤형 운동 및 영양학적 교육과 신체적, 정서적 만족감 향상의 기회를 제공하였다.

마지막으로, 창의융복합 교육모델인 『팀팀Class』를 통해 교수는 두 전공간의 교집합을 찾아냄으로써, 현장과 전공 연계성의 필요성 인식, 지역사회와의 연계 및 
다양한 관점에서 분석하고 융복합 교육 시스템을 만들어가야 한다는 점에서 새로운 연구의 기회이며, 전공 확장을 통해 융합의 시대를 이끌고 나가는 방향을 고민하는 계기를 마련할 수 있는 기회를 제공하였다.

본 연구를 통해 창의융복합 교육모델인 『팀팀Class』에서 체육대학 학생들이 참여한 사례분석이므로, 추후 연구에서는 교육모델의 타당성을 검증하기 위한 다른 학과가 참여한 수업 사례소개와 성과분석이 필요할 것으로 판단된다.

\section{References}

[1] Happy education where everyone grows, creative talents leading the future, Announcement of work plan, Ministry of Education, pp.1-13, (2017)

[2] A. J. Starko, Creativity in the classroom: Schools of Curious Delight (6td editon), Routledge, pp.1-138, (2017)

[3] Chung Yun Kim, Kyung Hwa Lee, Verification of 5C model for university student's creativity confluence competency, Asia-pacific Journal of Multimedia Services Convergent with Art, Humanities, and Sociology, (2017), Vol.7, No.7, pp.89-97, DOI: 10.35873/ajmahs.2017.7.7.009

[4] Choi Hye-Jin, A study on the Design Method of the Experience-based Liberal Arts Curriculum in University, Culture and Convergence, (2016), Vol.38, No.5, pp.39-70, UCI: G704-SER000003938.2016.38.5.014

[5] Naver, https://terms.naver.com/entry.naver?docId=612476\&cid=42126\&categoryId=42126), Dec 19 (2021)

[6] Some Assembly Required: STEM Skills and Canada's Economic Productivity, The Council of Canadian Academies, pp.77-99, (2015)

[7] Klaus Schwab, The Fourth Industrial Revolution, Portfolio Penguin, pp.1-192, (2016)

[8] https://www.kookmin.ac.kr/user/kmuNews/kmuEdu/0001/index.do, Nov 19 (2021)

[9] Yoon Ok-Han. Reviewing the Operation of Convergence and Related Complex Curriculums, as Demonstrated in the Context of K University, Culture and Convergence, (2021), Vol.43, No.6, pp.275-290, DOI: https://doi.org/10.33645/cnc.2021.06.43.6.275

[10] Park Jungwon, A Study of Case Studies on Craft and Design Convergence Education Programs -Focus on Kookmin University 「TeamTeam Class $\lrcorner$ Curriculums-, Journal of Digital Convergence, (2021), Vol.19, No.8, pp.327-335, DOI : $10.14400 /$ JDC.2021.19.8.327

[11] R. E. Riki, C. J. Jones, Senior Fitness Test Manual, Human Kinetics, pp.11-53, (2001)

[12] National Fitness Award 100, https://nfa.kspo.or.kr/front/certify/cer0303_list.do, Dec 19 (2021)

[13] https://blog.naver.com//kmu_unik/221483112785, Mar 8 (2019)

[14] Kim Jae-Deung, Won Yu-Mi, Yoo Jung-In, The Relationship between Exercise Emotion and Leisure Satisfaction of Elderly Exercise Participants, Journal of Coaching Development, (2021), Vol.23, No.3, pp.59-69, DOI: $10.47684 /$ jcd.2021.09.23.3.59

[15] Jae-ryong Lee, The Influence of Sports Confidence of Elderly Participating in Physical Education on Exercise Passion, Exercise Emotion and Psychological Happiness Hanil Graduate School, Ph.D dissertation, pp.47-75, (2021)

[16] Shin Jong-Soon, Lim Myoung-Jae, The Effect of Sociability Recovery and Life-satisfaction of Leisure Activity for Seniors, Journal of Exercise Rehabilitation, (2010), Vol.6, No.1, pp.55-64, UCI: G704-SER000008925.2010.6.1.013 